\title{
An Unjustified Prognosis of the Number of Asbestos-Related Lung Cancer Cases Caused by an Increase in Airborne Asbestos Concentrations as a Result of Removing of Asbestos-Cement Products
}

\author{
Neonila Szeszenia-Dąbrowska and Beata Świątkowska \\ Nofer Institute of Occupational Medicine, Department of Environmental Epidemiology, \\ The Reference Center for Asbestos Exposure \& Health Risk Assessment, Teresy 8, 91-348 Łódź, Poland \\ Correspondence should be addressed to Neonila Szeszenia-Dąbrowska; wies@imp.lodz.pl
}

Received 9 February 2015; Accepted 16 March 2015

Academic Editor: Benedetto Terracini

Copyright ( 2015 N. Szeszenia-Dąbrowska and B. Świątkowska. This is an open access article distributed under the Creative Commons Attribution License, which permits unrestricted use, distribution, and reproduction in any medium, provided the original work is properly cited.

We have read the recently published article under an interesting title "Environmentally Related Diseases and the Possibility of Valuation of Their Social Costs" by I. Hajok et al. [1], the main objective of which was "to estimate the risks of the morbidity of the asbestos-related lung cancer in the general population of Poles as the result of increased exposure to asbestos fibers which occurs during the removal and disposal of asbestos-cement products in Poland."

Contrary to mesothelioma, considered to be a neoplasm specific to environmental exposure to asbestos [2-6], the risk of lung cancer is rarely a subject of analysis in the context of environmental exposure of residents. It is, among others, due to having no features of neoplasm that enable the indication of asbestos as a causative factor, as well as numerous competitive factors of the incidence of this neoplasm. According to the recommendations of the experts of $\mathrm{WHO}$, in the case of this kind of neoplasm, the only practical approach is to use the population attributable fraction (PAF) $[7,8]$. Therefore, the published article is even more noteworthy; its contents raise a number of questions and doubts concerning both substantive bases and methodological approach to the analysis.

Firstly, the statement "increased exposure to asbestos fibers which occurs during the removal and disposal of asbestos-cement products in Poland" does not find its confirmation in the published papers. The size of asbestos fibers concentrations during removal of asbestos-cement products was in Poland a subject of numerous measurements taken on various work posts as well as in the atmospheric air. The published results do not confirm the thesis concerning both high concentrations of asbestos fibers during products dismantling as well as, related to these works, a considerable increase in the concentration of asbestos fibers in the atmospheric air, provided safe and legally regulated methods of work are applied [9-13].

Secondly, description of the method is limited to a very vague statement: "Taking into consideration the concentration of asbestos fibers in the air of particular administrative area and the number and type of former plants producing asbestos-cement products, as well as standardized incidence rates (SIR) of asbestos-dependent diseases (...) three zones of the country with varying degrees of risk of asbestos-related disease were isolated." In order to make it possible for the readers to get familiar with the method applied, a reference number [14] was indicated. However, in that paper we do not find answers to any of the elementary questions, inter alia, what does "type of former plants producing asbestoscement products" mean and how was it determined; there is also no description of the method for calculating standardized incidence rates (SIR) of asbestos-related diseases, which turned out to be cases of occupational diseases diagnosed in 
Poland. Occupational asbestos-related diseases reported in Poland over the years 2001-2009, which the authors used to determine the 3 zones of environmental exposure to asbestos, are a result of exposure in the 70 s and 80 s of the previous century. During that period concentrations on the work posts ranged from 2 to $8 \mathrm{f} / \mathrm{cm}^{3}$, that is, from 2.000 .000 to $8.000 .000 \mathrm{f} / \mathrm{m}^{3}$ of air [15], whereas mean concentrations in the atmospheric air estimated in all provinces of Poland based on the total of 5962 samples for 1634 sampling sites amounted to about $500 \mathrm{f} / \mathrm{m}^{3}$ of air, exceeding $1000 \mathrm{f} / \mathrm{m}^{3}$ [13] only in few points.

Thirdly, based on the description of the method one should presume that in the extrapolation of the incidence of occupational asbestos-related lung cancer (from the area of high doses) in the case of the risk of incidence of lung cancer caused by environmental exposure in the general population (to the area of low doses) occurrence of the same risk was assumed and no coefficient reflecting the size of exposure was applied.

It seems reasonable then to ask what are the substantive grounds for using "incidence ratio" of occupational asbestosrelated diseases for the purpose of forecasting the number of lung cancer cases caused by environmental exposure related to dismantling of asbestos-cement products? It should be emphasized that, among individuals who are exposed paraoccupationally and environmentally, the literature has not reported any cases of asbestosis, which constitutes about $60-70 \%$ of the total number of cases of occupational diseases induced by asbestos $[15,16]$.

In conclusion, if presented in the article estimation of the risk of incidence of lung cancer associated with exposure to asbestos dust during removal, securing, and dismantling of products, mainly asbestos-cement ones, in the general population of Poland was reliable, the works would contribute to the incidence of 14 thousand new cases of lung cancer. In such a situation the only conclusion is to call for the immediate cessation of the "Programme for Asbestos Abatement in Poland 2009-2032."

\section{Conflict of Interests}

The authors state that there is no conflict of interests regarding the publication of this paper.

\section{References}

[1] I. Hajok, E. Marchwińska, G. Dziubanek, B. Kuraszewska, and A. Piekut, "Environmentally related diseases and the possibility of valuation of their social costs," The Scientific World Journal, vol. 2014, Article ID 284072, 6 pages, 2014.

[2] IARC Working Group Asbestos, "Chrysotile, amosite, crocidolite, tremolite, actinolite and anthophyllite," in IARC Monographs on the Evaluation of Carcinogenic Risks to HumansA Review of Human Carcinogens: Arsenic, Metals, Fibres, and Dusts, vol. 100, pp. 219-309, International Agency for Research on Cancer, Lyon, France, 2012, http://monographs .iarc.fr/ENG/Monographs/vol100C/ mono100C.pdf.
[3] A. Tossavainen, "Global use of asbestos and the incidence of mesothelioma," International Journal of Occupational and Environmental Health, vol. 10, no. 1, pp. 22-25, 2004.

[4] R.-T. Lin, K. Takahashi, A. Karjalainen et al., "Ecological association between asbestos-related diseases and historical asbestos consumption: an international analysis," The Lancet, vol. 369, no. 9564, pp. 844-849, 2007.

[5] V. Delgermaa, K. Takahashi, E.-K. Park, G. V. Le, T. Hara, and T. Sorahan, "Global mesothelioma deaths reported to the World Health Organization between 1994 and 2008," Bulletin of the World Health Organization, vol. 89, no. 10, pp. 716-724, 2011.

[6] T. Kameda, K. Takahashi, R. Kim et al., "Asbestos: use, bans and disease burden in Europe," Bulletin of the World Health Organization, vol. 92, no. 11, pp. 790-797, 2014.

[7] T. Driscoll, K. Steenland, A. Prüss-Üstün et al., Occupational Carcinogens: Assessing the Environmental Burden of Disease at National and Local Levels, World Health Organization, Geneva, Switzerland, 2004, http://www.who.int/quantifyingehimpacts/publications/en/ebd6.pdf.

[8] The Human and Financial Burden of Asbestos in the WHO European Region, Meeting report; 2012 Nov 5-6, Bonn, Germany, World Health Organization Regional Office for Europe, Copenhagen, Denmark, 2013, http://www.euro.who .int/__data/assets/pdf_file/0003/194133/RB-Asbestos-Mtg-Report-Bonn-2012.pdf.

[9] J. Dyczek, "Surface of asbestos-cement (AC) roof sheets and assessment of the risk of asbestos release," in Proceedings of the International Seminar held in AGH on Asbestos Risk Reduction and Measurement of Asbestos Fibre Concentration, J. Dyczek, Ed., Appendix, pp. 57-63, AGH University of Science and Technology, Cracow, Poland, September 2006.

[10] G. Stroszejn-Mrowca and I. Szadkowska-Stańczyk, "Monitoring of environment and evaluation of occupational exposure to asbestos dust during removal of asbestos product from environment," in Asbestos Risk Reduction and Measurement of Asbestos Fibre Concentration, Proceedings of the International Seminar held in AGH, Appendix, 28-29 September 2006. Cracow, Poland, J. Dyczek, Ed., pp. 21-24, AGH University of Science and Technology, 2006.

[11] S. Bujak-Pietrek and I. Szadkowska-Stańczyk, "Narażenie na dzialanie respirabilnych włókien azbestu podczas różnych etapów prac związanych z usuwaniem materiałów azbestowych (Exposure to respirabile asbestos fibers at various stages of asbestos removal work)," Medycyna Pracy, vol. 63, no. 2, pp. 191198, 2012 (Polish).

[12] E. Krakowiak, R. L. Górny, J. Cembrzyńska, G. Saksol, M. Boissier-Draghi, and E. Anczyk, "Environmental exposure to airborne asbestos fibres in a highly urbanized city," Annals of Agricultural and Environmental Medicine, vol. 16, no. 1, pp. 121128, 2009.

[13] N. Szeszenia-Dabrowska, W. Sobala, B. Swiatkowska, G. Stroszejn-Mrowca, and U. Wilczynska, "Environmental asbestos pollution-situation in Poland," International Journal of Occupational Medicine and Environmental Health, vol. 25, no. 1, pp. 3-13, 2012.

[14] I. Hajok, Forecast of health effects in population of Poles as a result of exposure to asbestos dust [Ph.D. thesis], Medical University of Silesia, Katowice, Poland, 2011, (Polish). 
[15] N. Szeszenia-Dabrowska, B. Świațowska, Z. Szubert, and U. Wilczyńska, "Asbestos in Poland: occupational health problems," International Journal of Occupational Medicine and Environmental Health, vol. 24, no. 2, pp. 142-152, 2011.

[16] N. Szeszenia-Dąbrowska and U. Wilczyńska, "Asbestos-related diseases," in Occupational Diseases in Poland. Statistics and Epidemiology, pp. 31-40, NIOM, Łódź, Poland, 2007, (Polish). 


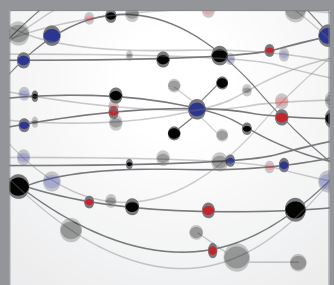

The Scientific World Journal
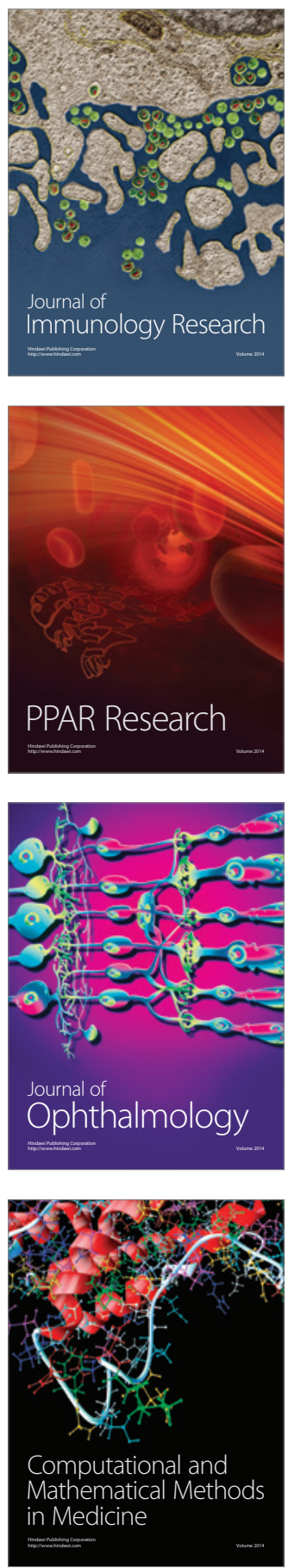

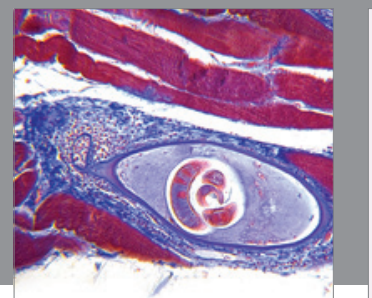

Gastroenterology

Research and Practice
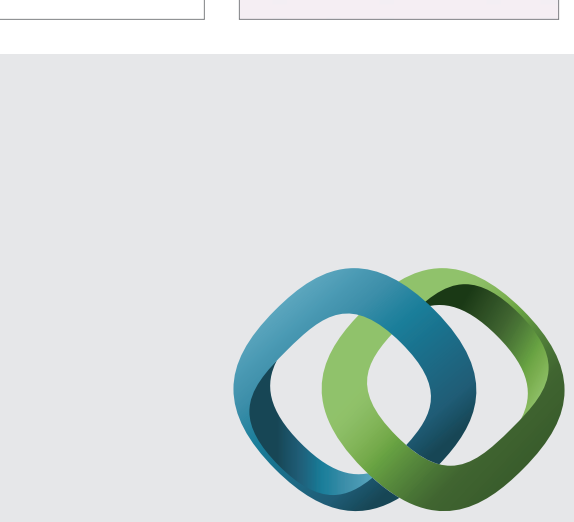

\section{Hindawi}

Submit your manuscripts at

http://www.hindawi.com
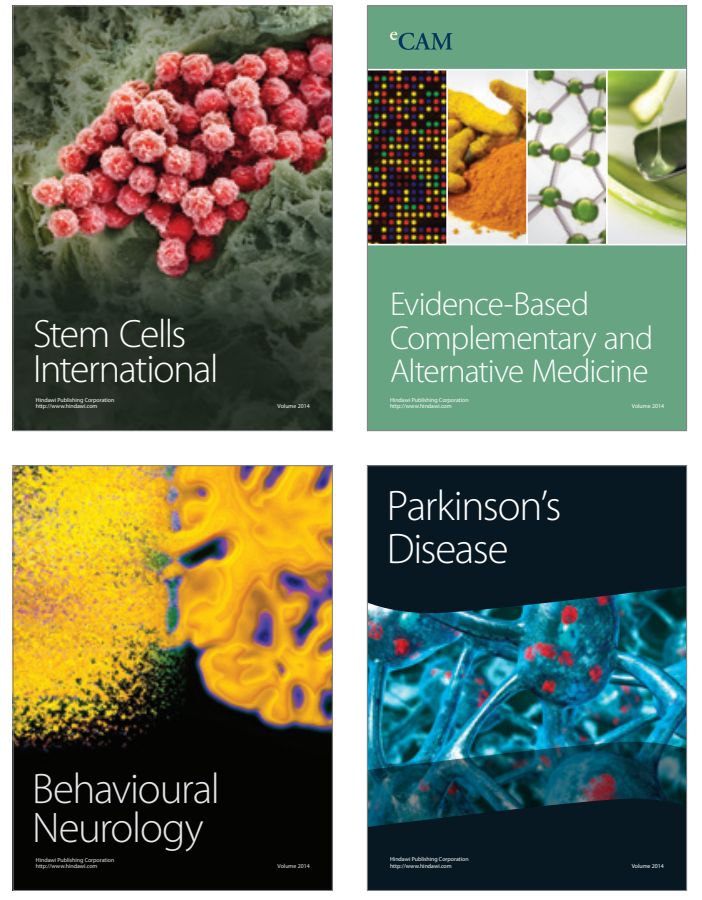
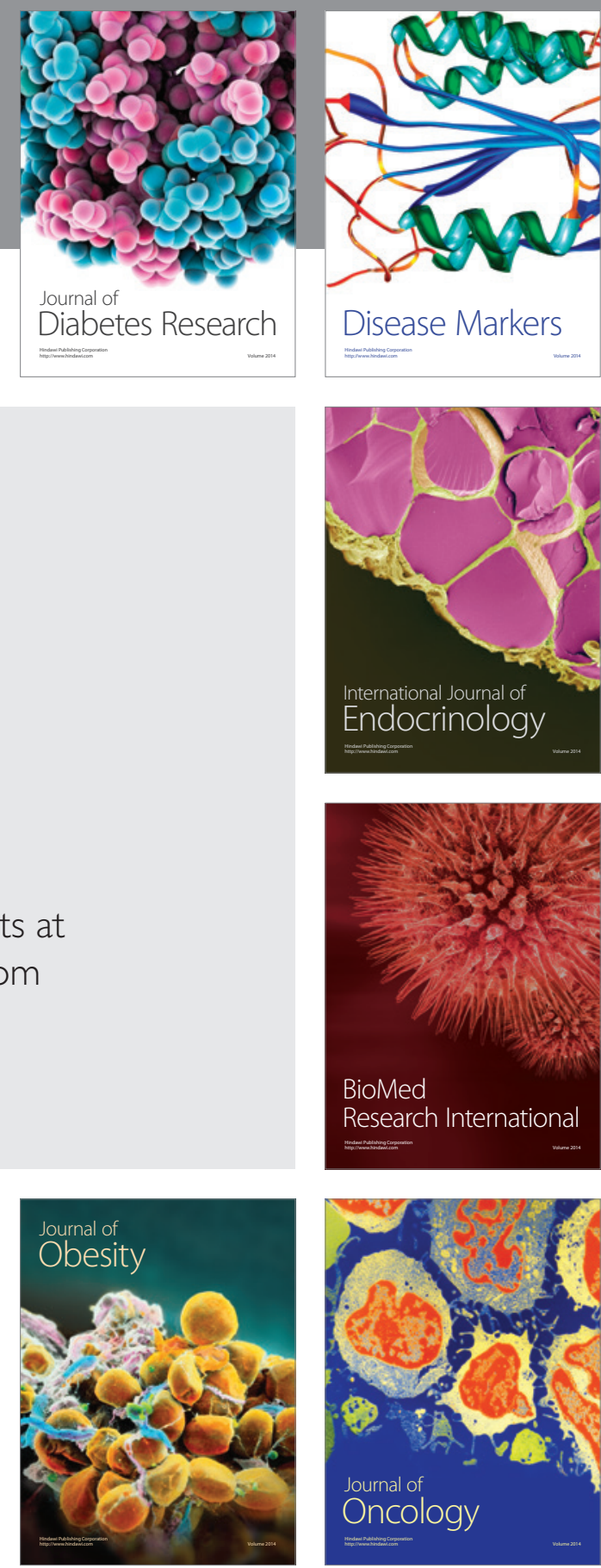

Disease Markers
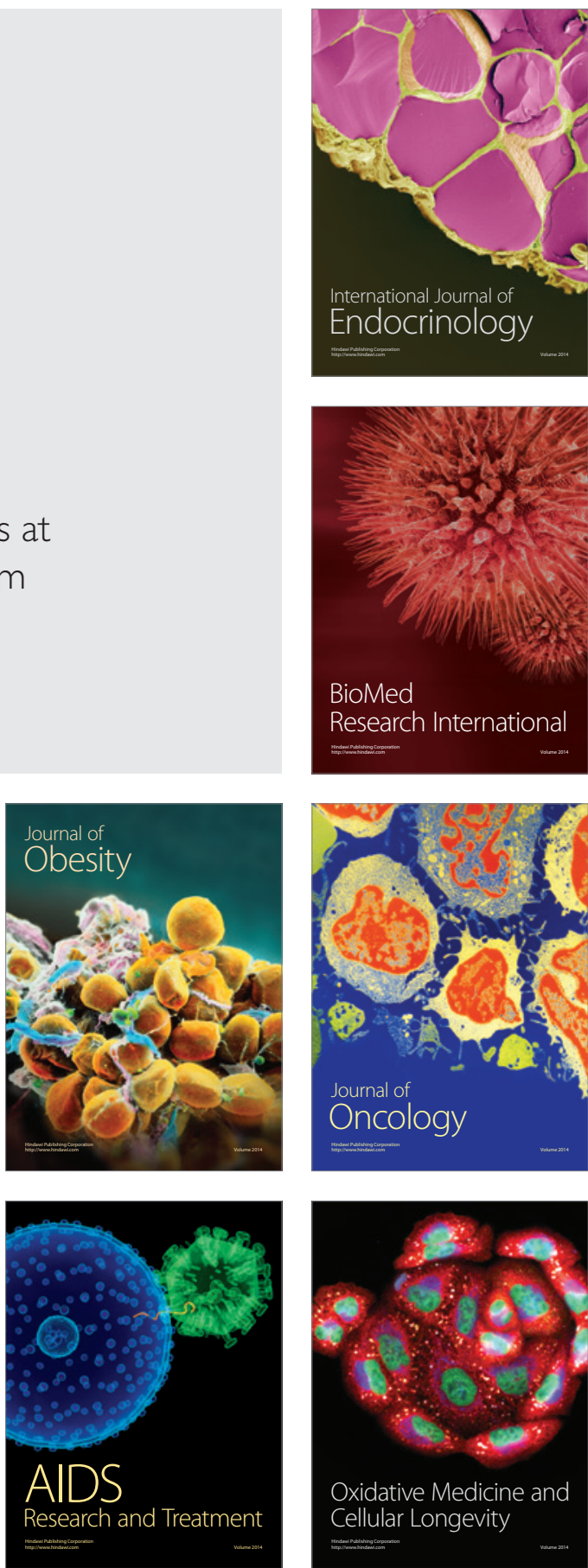